\title{
Improving infrastructure sustainability in suburban and urban areas: is porous asphalt the right answer? and how?
}

\author{
F. G. Praticò $^{1} \&$ R. Vaiana ${ }^{2}$ \\ ${ }^{1}$ DIMET Department, Mediterranea University, Reggio Calabria, Italy \\ ${ }^{2}$ DiPiTer Department, University of Calabria, Arcavacata Campus, \\ Cosenza, Italy
}

\begin{abstract}
The goal of this paper is to investigate transportation infrastructure sustainability from a wider standpoint.

A sustainable transportation infrastructure can be defined as a safe, efficient, economic, environmentally friendly infrastructure meeting the needs of presentday users without compromising those of future generations. This concept involves environmental, economic and societal aspects.

In more detail, as for a road, a sustainable infrastructure or pavement must comply with environmental, economic and social requirements.

Unfortunately, even if a definition of a sustainable pavement for urban or suburban areas can be easily proposed, the proposal of practical strategies to really pursue sustainability goals is sometimes disregarded in favour of emphatic announces of not well defined sustainable solutions.

In the light of the above facts, the sustainability of a transportation infrastructure based on the actual environmental, social and economic characteristics is discussed in this paper. Once the main factors which can influence infrastructure sustainability are assessed, an analysis is performed in order to set out practical strategies for pursuing the main objective.

Finally an experimental investigation is designed and carried out in order to assess porous asphalt value in terms of pavement sustainability. The tests carried out are promising about the possibility of achieving suitable levels of overall performance. Practical applications and perspectives in rehabilitation, maintenance, and research are outlined.

Keywords: rehabilitation, porous European mixes (PEM), reclaimed asphalt pavement $(R A P)$, recycling, surface performance.
\end{abstract}




\section{Introduction}

As is well known, the word sustainability is derived from the Latin sustinere (to hold). According to the Brundtland Commission of the United Nations (March 20, 1987), sustainable development is development that meets the needs of the present without compromising the ability of future generations to meet their own needs. If we refer to the WWF (World Wildlife Fund) definition (1991), sustainability is improving the quality of human life while living within the carrying capacity of supporting eco-systems, while the so-called Earth Charter refers to a sustainable global society founded on respect for nature, universal human rights, economic justice, and a culture of peace. According to 2005 World Summit, sustainability deals with the reconciliation of environmental, social and economic demands - the "three pillars" of sustainability (triple bottom line). Some researchers and institutions have pointed out that these three dimensions are not enough to reflect the complexity of contemporary society and suggest that culture could be included in this development model. On the other hand for many environmentalists the idea of sustainable development is an oxymoron as development seems to entail environmental degradation.

It is noted that the term sustainability has been applied to a number of concepts: human sustainability on Earth, sustainable agriculture, sustainable development, sustainable architecture, sustainable energy, sustainable tourism, sustainable building, and sustainable infrastructure. As for Green Buildings, there is a number of Environmental Rating Systems dealing with: Siting; Energy Efficiency (Materials Efficiency); Use of Recycled Materials; Water Efficiency; Occupant Health and Safety; Building Operations and Maintenance. Developed by the U.S. Green Building Council (USGBC) in 2000, the LEED rating systems (where LEED stands for Leadership in Energy and Environmental Design) are developed through a consensus-based process led by LEED committees.

A sustainable transportation infrastructure can be defined as a safe, efficient, economic, environmentally friendly infrastructure meeting the needs of presentday users without compromising those of future generations [1]. This concept involves again environmental, economic and societal aspects. As for Sustainable Pavement Technologies the following main classes can be listed: i) Recycling; ii) Reuse; iii) Other Technologies.

To this end it is noted that sustainable technologies comprise Recycling Applications (Reclaimed Asphalt Pavement, Recycled Concrete Aggregate, InPlace Recycling), Reuse Applications (Fly Ash/Coal Ash, Tire Rubber, Shingles, Slag, Foundry Sand) and Warm-Mix Asphalt.

In more detail, it is noteworthy to point out that recycling implies reducing project costs, conserving materials, reuse high quality aggregates unavailable, dwindling landfill use, diminishing disposal costs. For example, 30000 tons of RAP correspond to approximately 700 transport trailers each one of about 23 cubic meters (6000 gallons). The US greenroads rating system is based on seven main categories: project requirements, environment and water; access and equity; construction activities; materials and resources; pavement technology; custom credits. Each category has a detailed description and can correspond (for 
a given case-study or project) to a given score. Based on points, the project is classified as silver (31-38 points), gold (39-46 points), and evergreen (more than 47 points). In the same US greenroads rating system the life cycle analysis (LCA) is considered a valuable methodology. In more detail, when analysing HMA (Hot mix asphalt) LCA, the following issues/steps/inputs/outputs are considered: i) oil extraction, transport, refinery, transport; ii) other inputs such as water and fuel; iii) aggregates (aggregate quarry, transport; iii) HMA plant (transport, placement); iv) other outputs (emissions, waste, hazardous waste, recycling).

According to FHWA's "3 Es" philosophy, the following three main instances are relevant in terms of pavement sustainability: i) engineering (use good engineering design to assure long-life pavements); ii) economics (use life-cycle cost analysis for project selection); iii) environment (consider recycling first; be good stewards of the environment).

As far as the MTO (Ontario Ministry of Transportation) approach is considered, the sustainability of HMA recycling implies the consideration of [1-12]: i) materials \& resources; ii) pavement technologies; iii) energy and atmosphere; iv) innovation and design process.

Permeable friction courses are growing in importance as a potential answer to improve sustainability potential of friction courses. PEMs (Porous European mixes) and TLPAs (Two-layer porous asphalts) are two types of permeable friction courses.

PEMs (air void content usually in excess of $20 \%$ ) act as a wearing course $50 \mathrm{~mm}$-thick on impermeable base courses and have well-known points of strength: reduction of splash and spray, mitigation of outdoor noise (high porosity, low flow resistivity), optimization of skid resistance at high speeds in wet conditions (high macrotexture). In contrast, PEMs have several points of weakness: clogging, variation of noise, texture, friction, and permeability performance over the time. TLPAs consist of two layers of the well-known porous asphalt and have been found to be effective in terms of noise absorption and less prone to clogging. When the life cycle of permeable friction courses ends, the friction course is milled and rehabilitation is needed.

Furthermore, to this end, it is relevant to point out that one of the key problems with RAP (reclaimed asphalt pavement) mixes is its variability, which is the main reason why many states and agencies limit the use of RAP. In most circumstances, RAP variability is closely related to RAP stockpiles management and RAP processing.

As for innovation \& design process, recycling PEMs back to other permeable friction courses requires the innovative consideration of many issues [13, 14]: hot or cold milling process, use of RAP in premium surface course mixes, variability of RAP, non-linearity in the blending equations for percentages of RAP greater than $40 \%$, issues pertaining the recycling techniques of RAP containing high viscosity modified asphalt, actual impact of RAP aggregates, effective gravity vs. bulk specific gravity use for from-RAP aggregates. Finally it is noted that from an economic standpoint, PEMS cost more than traditional 
dense-graded friction courses (if we refer to the cost per square meter, about two times).

In the light of the above facts and analyses, an experimental investigation was designed and carried out in order to assess porous asphalt value in terms of pavement sustainability. The remaining part of the paper is organized as follows. Section 2 refers to experiments and discussion. In section 3 conclusions are drawn.

\section{Experiments and discussion}

In order to allow the production of a TLPA (two-layer porous asphalt), around $82 \%$ of RAP (from PEM) was used. Three lots of RAP were used (M1, M2, M3). The lots M2 and M3 resulted in being the most different, while the gradation of the lot M1 resulted in being close to the average between M2 and M3. For each RAP lot, different size gradations of RAP were mixed in order to fulfill functional properties (permeability and drainability), grading requirements, volumetrics, mechanical requirements, and desired thickness of both the top and the bottom layer (Figure 1). It is noted that the experimental plan was carried out under the auspices of the research project of national interest, PRIN 2008, Research Project "Drenante da drenante" (Universities of Reggio Calabria and Cosenza - Italy). Figure 1 and Table 1 summarize the experimental plan.

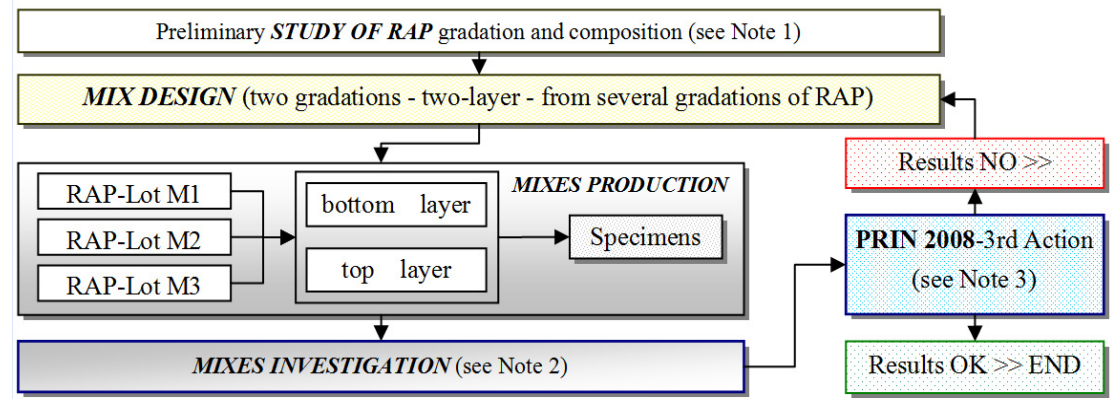

Figure 1: Summary of experiments and analyses.

Table 1: $\quad$ Summary of the experimental plan.

\begin{tabular}{|c|c|c|c|c|c|c|c|c|}
\hline \multirow[t]{2}{*}{$\begin{array}{l}\text { RAP } \\
\text { lot }\end{array}$} & \multicolumn{4}{|c|}{$\begin{array}{l}\text { Segregation of each RAP lot } \\
\text { into five gradations }\end{array}$} & \multicolumn{3}{|c|}{$\begin{array}{c}\text { From } 5 \text { gradations } \\
\text { to two mixes } \\
\text { - many trials - }\end{array}$} & \multirow[t]{2}{*}{$\begin{array}{c}\text { Best and } \\
\text { worst results }\end{array}$} \\
\hline & & & & & trial a & trial b & $\ldots$ & \\
\hline M1 & M11 & M12 & $\ldots$ & M15 & $\begin{array}{l}\text { TOP1a, } \\
\text { BOT1a }\end{array}$ & $\begin{array}{l}\text { TOP1b, } \\
\text { BOT1b }\end{array}$ & 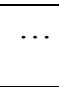 & \multirow{3}{*}{$\begin{array}{l}\mathrm{H}=\text { worst } \\
\text { mix- result; } \\
\mathrm{J}=\text { best mix- } \\
\text { result. }\end{array}$} \\
\hline M2 & M21 & M22 & $\ldots$ & M25 & $\begin{array}{l}\text { TOP2a, } \\
\text { BOT2a }\end{array}$ & $\begin{array}{l}\text { TOP2b, } \\
\text { BOT2b }\end{array}$ & $\ldots$ & \\
\hline M3 & M31 & M32 & $\ldots$ & M35 & $\begin{array}{l}\text { TOP3a, } \\
\text { BOT3a }\end{array}$ & $\begin{array}{l}\text { TOP3b, } \\
\text { BOT3b }\end{array}$ & $\ldots$ & \\
\hline
\end{tabular}


- Note 1. Asphalt binder extraction $\rightarrow$ Asphalt binder recovery by Rotavapor $\rightarrow$ Penetration, Softening point, Viscosity, Ductility, Elastic recovery etc. Analysis of two-layer porous asphalts (composition and volumetrics);

- Note 2. Analysis of composition, volumetrics, functional and mechanical performance of bottom and top samples: $b=$ asphalt binder content (by weight of aggregates): UNI EN 12697-1; G: Aggregate gradation; UNI EN 12697-2; Gmb: bulk Specific gravity; standard: AASHTO TP 69; Gsb: stone bulk specific gravity; standard: ASTM D 6752; AV: air voids content; standard: UNI EN 12697-8; RM : Marshall resistance; standard: UNI EN 12697-34; MQ : Marshall quotient; standard: UNI EN 12697-34; MF: Marshall Flow; standard: UNI EN 12697-34. ITS: indirect tensile strength; standard: UNI EN 12697-23 $\left(\mathrm{T}=25^{\circ} \mathrm{C}\right)$; K: permeability; standard ASTM PS 129;

- $\quad$ Note 3. Analysis and comparison with predicted results of the national project PRIN 2008-III Action.

Figures 2 to 7 and table 2 summarize the results we obtained.

Table 2: $\quad$ Composition and Volumetrics of top and bottom mixes.

\begin{tabular}{|c|c|c|c|c|c|c|}
\hline & \multicolumn{3}{|c|}{ H test } & \multicolumn{3}{c|}{ J test } \\
\cline { 2 - 7 } & $\mathrm{b} \%$ & $\begin{array}{c}\mathrm{Gmb} \\
\left(\mathrm{g} / \mathrm{cm}^{3}\right)\end{array}$ & $\begin{array}{c}\mathrm{Gsb} \\
\left(\mathrm{g} / \mathrm{cm}^{3}\right)\end{array}$ & $\mathrm{b} \%$ & $\begin{array}{c}\mathrm{Gmb} \\
\left(\mathrm{g} / \mathrm{cm}^{3}\right)\end{array}$ & $\begin{array}{c}\mathrm{Gsb} \\
\left(\mathrm{g} / \mathrm{cm}^{3}\right)\end{array}$ \\
\hline Top & 5.2 & 2.124 & 2.235 & 4.9 & 2.845 & 2.827 \\
\hline Bottom & 5.2 & 2.416 & 2.200 & 4.3 & 2.826 & 2.851 \\
\hline
\end{tabular}
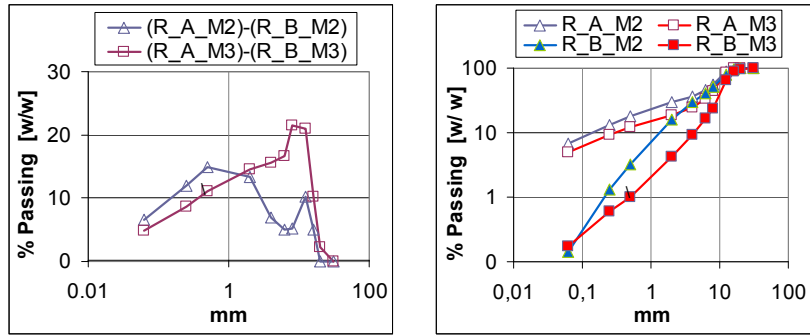

Figure 2: $\quad$ RAP gradation before (R_B_M2, R_B_M3) and after (R_A_M2, R_A_M3) the extraction of asphalt binder - Lots M2 and $\bar{M} 3$.

Figure 2 illustrates RAP gradation before (R_B) and after the extraction (R_A) and Figure 3 shows the main tests carried out on the recovered asphalt binder. Note that: $\mathrm{Pb}$ ' stands for asphalt binder content by weight of aggregate (\%, EN 12697-6); $\mathrm{P}$ is the penetration (0.1 mm, EN 1426-7); SP stands for softening point $\left({ }^{\circ} \mathrm{C}, \mathrm{EN} 1427-7\right)$; D is the ductility at $25^{\circ} \mathrm{C}(\mathrm{cm}$, ASTM D11386, CNR B.U. N. 44/74); ER stands for Elastic Recovery $\left(=(\mathrm{d} / 200)^{*} 100, \%\right.$, EN 13398-3); the viscosity is expressed in mPas (ASTM D4402-06); the Richness modulus of the reclaimed pavement was derived according to [16-19]. 


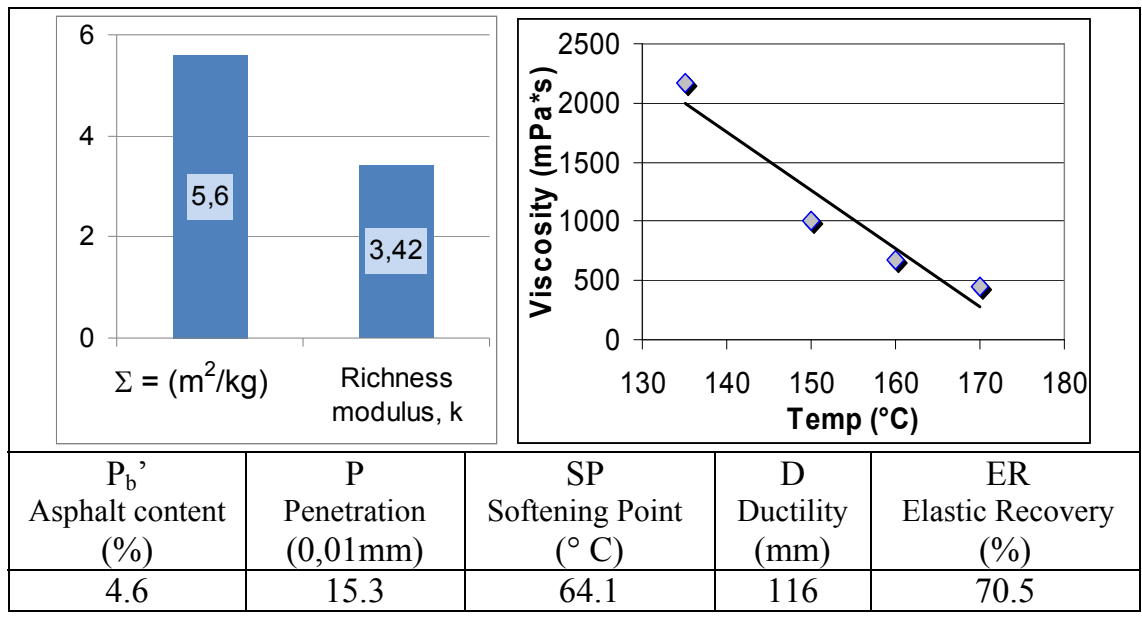

Figure 3: Richness modulus and recovered asphalt binder characteristics. LEGEND: $\mathrm{k}=\mathrm{P}_{\mathrm{b}} /\left(\alpha \cdot \Sigma^{0.2}\right) ; \mathrm{P}_{\mathrm{b}}=$ Asphalt content by weight of mix $(\%) ; \Sigma=0.25 \mathrm{G}+2.3 \mathrm{~S}+12 \mathrm{~s}+135 \mathrm{f} \quad(\mathrm{G}:>6.3 \mathrm{~mm} ; \mathrm{S}$ : between 6.3 and $0.315 \mathrm{~mm}$; s: between 0.315 and $0.08 \mathrm{~mm}$; f: $<0.08 \mathrm{~mm}) ; \alpha=$ $2.65 / \mathrm{G}_{\mathrm{SE}} ; \quad \mathrm{G}_{\mathrm{SE}}=\left(100-\mathrm{P}_{\mathrm{b}}\right) /\left(\left(100 / \mathrm{G}_{\mathrm{mm}}\right)-\left(\mathrm{P}_{\mathrm{b}} / \mathrm{G}_{\mathrm{b}}\right)\right) ; \quad \mathrm{G}_{\mathrm{SE}}$ : effective specific gravity of aggregate; $\mathrm{G}_{\mathrm{mm}}$ : maximum theoretical specific gravity of the HMA mixture; $G_{b}$ : bitumen specific gravity.

Figure 4 and table 2 illustrate the composition and volumetric characteristics we obtained for the $\mathrm{H}$ and $\mathrm{J}$ tests.

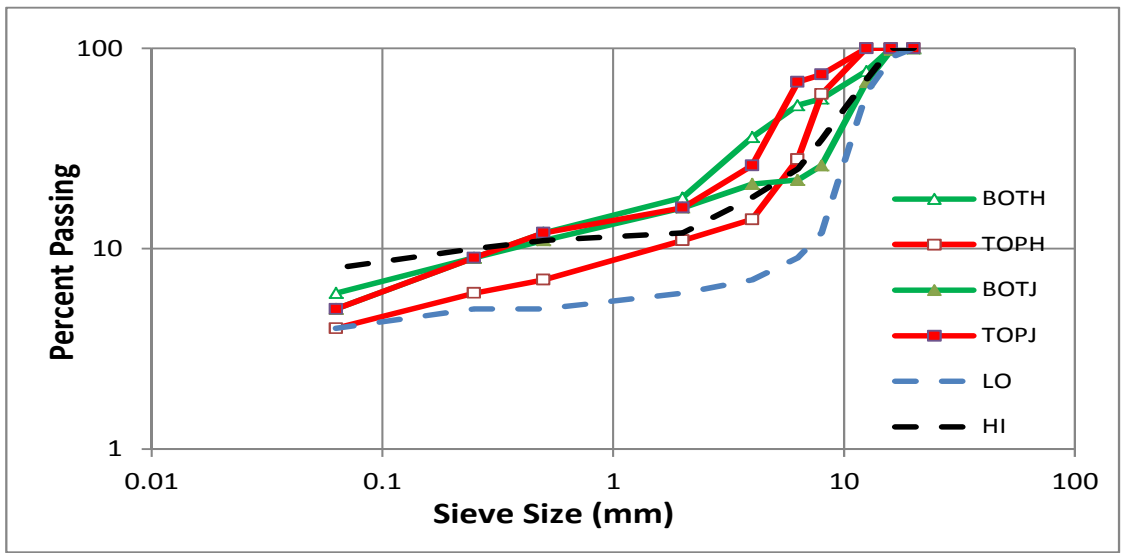

Figure 4: $\quad$ Gradations of the top (TOP) and bottom (BOT) layer $-\mathrm{H}$ and $\mathrm{J}$ test. NOTE. LO and HI represent the boundaries of the allowed gradations according to Italian specifications. 
In the $\mathrm{H}$ tests the permeability of the bottom layer resulted unsatisfactory (see Figure 5), air voids content ranged from 5 to $9 \%$ and aggregate gradation showed an excess of sand. The analysis of surface texture [20-21] confirmed that the bottom layer resulted in an intermediate configuration between a dense-graded and an open-graded course (see Figure 5). On the contrary, top layer showed an air void content of $16-20 \%$. For both the layers, the relationship between permeability and air void content resulted consistent with [6-22]. Both for the top and the bottom layer, in the J tests, air void content and permeability resulted closer to the target than in the $\mathrm{H}$ tests.

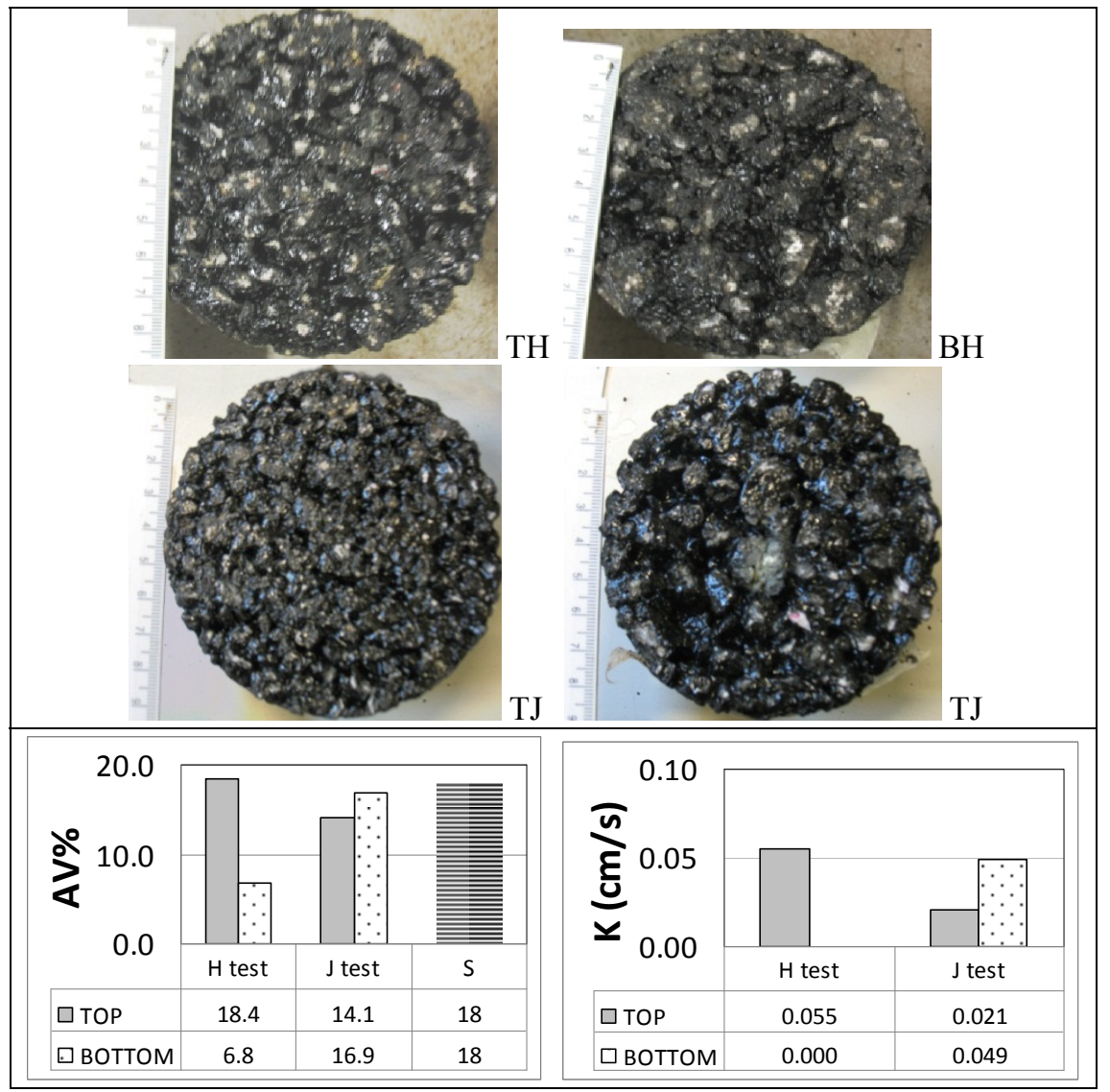

Figure 5: $\quad$ Air void, permeability and texture (Marshall samples). Top layer Ti and bottom layer $\mathrm{Bi}$ for $\mathrm{i}=\mathrm{H}$ and $\mathrm{J}$ tests. NOTE. $\mathrm{S}=$ lower limit from Italian specification.

Marshall and indirect tensile strength tests (ITS, see Figures 6 and 7) were used to provide an indication of the mechanical performance of asphalt mixtures. The European standard UNE-EN 12697-23:2004 test was used for evaluating the 

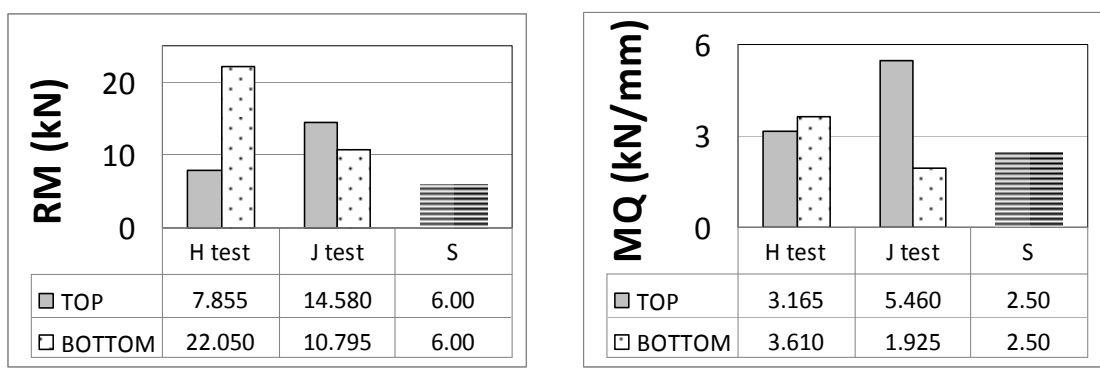

Figure 6: Marshall stability (RM) and quotient (MQ). NOTE. S = lower limit from Italian specification.

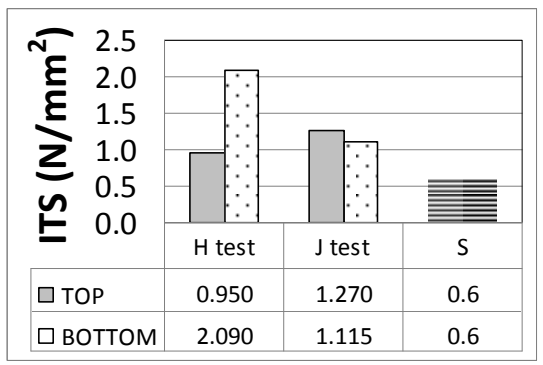

Figure 7: Indirect Tensile Strength (ITS). NOTE. S = lower limit from Italian specification.

ITS of the mixtures. Temperature was $25^{\circ} \mathrm{C}$ and velocity was $50.8 \mathrm{~mm} / \mathrm{min}$. Cylindrical specimens were broken by applying a compressive load along the vertical diameter. ITS was determined by the expression ITS $=2 \mathrm{P} /(\pi \cdot \mathrm{D} \cdot \mathrm{h})$, where ITS is the indirect tensile strength $\left(\mathrm{N} / \mathrm{mm}^{2}\right), P$ is the applied load $(\mathrm{N}), \mathrm{D}$ is the specimen diameter $(\mathrm{mm})$ and $\mathrm{h}$ is the specimen thickness $(\mathrm{mm})$. In both the $\mathrm{H}$ test and the $\mathrm{J}$ test, the mechanical performance of the two layers resulted almost satisfactory. It is important to remark that the several sources of variability were involved and considered. Although RAP was derived always from the same stockpile obtained from the cold milling the same pavement, RAP Management (fractionating, stockpile management practices, etc.), material heterogeneity (RAP Asphalt Content \& Gradation) and other sources of variations caused RAP variability [23-28]. Despite this, it is noted that due to the use of a very high percentage of RAP, experiments demonstrate that the solutions proposed meet a number of sustainability requirements [29-31]. Furthermore, these facts illustrate the potential and suitability of the designed mixes for improved pavement life cycles [32-35]. 


\section{Conclusions}

Improving infrastructure sustainability in suburban and urban areas is a complex task for many reasons. The same concept of sustainability is in evolution and a number of methods and logical frameworks have been proposed in the field of transport infrastructure and pavement sustainability. Under these premises in this paper we investigated on the suitability of porous asphalt concretes to address several requirements pertaining pavement sustainability.

Indeed, the goal of this paper was to investigate transportation infrastructure sustainability. Once assessed the main factors which can influence infrastructure sustainability an experimental investigation was carried out in order to assess porous asphalt value and suitability in terms of pavement sustainability.

Efforts were focused into the optimization of the sustainability of PEMs rehabilitation, through the recycling of PEMs back to innovative, silent, permeable road surfaces. Around the $82 \%$ of RAP was used and a two-layer porous asphalt was derived from the reclaimed asphalt pavement. Three main RAP gradations were used. The recycled, high-RAP content mixes were produced and tested. Mechanical performance was adequate. Functional performance resulted promising. Although several issues call for further research, the tests carried out are encouraging about the possibility of achieving a satisfactory level of surface performance notwithstanding RAP variability issues. Practical applications mainly refer to the design and rehabilitation of porous European mixes in suburban and urban areas. Under the above premises porous asphalt (eventually recycled in terms of TLPAs) can be considered a viable solution for improving infrastructure sustainability in suburban and urban areas. Outcomes of this study are expected to benefit both practitioners and researchers. Further research will be needed to complete the study aimed at gaining a more comprehensive understanding of TLPA long-term performance and rehabilitation.

\section{Acknowledgements}

The authors want to thank Eng. Antonino Moro (University Mediterranea at Reggio Calabria), Eng. Franco De Masi (University of Calabria) and Eng. Teresa Iuele (University of Calabria).

\section{References}

[1] Chan S., Lane B., Kazmierowski T. (2011). "Pavement preservation - a solution for sustainability", Proc., Transportation Research Board 2011 Annual Meeting.

[2] Kandhal Prithvi S., Mallick Rajib B. (1997). "Pavement Recycling Guidelines for State and Local Governments Participant's." Reference Book, National Center for Asphalt Technology, Publication No. FHWASA-98-042. 
[3] Thenoux, G., Gonzalez, A., Dowling, R. (2007). "Energy consumption comparison for different asphalt pavements rehabilitation techniques used in Chile Resources." Conservation and Recycling 49 325-339.

[4] Hamzah M.O., Hardiman, C., (2005). "Characterization of the clogging behaviour of double layer porous asphalt." Journal of the Eastern Asia Society for Transportation Studies, Vol. 6, pp. 968-980, 2005.

[5] Hardiman, M. Y. (2008). "The Comparison of Engineering Properties Between Single and Double Layer Porous Asphalt made of Packing Gradation." Civil Engineering Dimension, Vol. 10, No. 2, 82-88.

[6] Praticò F.G., Moro A. (2008). "Flow of Water in Rigid Solids: Development and Experimental Validation of Models for Tests on Asphalts, Modeling granularity" - Special Issue of "Computers \& Mathematics with Applications", Publisher: Elsevier Science, ISSN 08981221, vol.55, issue 2, pages 235--244.

[7] Woldemariam W., Olek J., McDaniel R.S., (2011) European HMA Mixture Design Practices for Tire-Pavement Noise Reduction, Proceedings of the 2011 TRB Annual Meeting, Washington DC.

[8] Praticò F.G., Vaiana R., Giunta M. (2011). Can you really recycle PEMs back to PEMs and be confident also on surface properties? - Proceeding of XXIVth AIPCR World Road Congress, Mexico City, in press.

[9] Praticò F.G., Vaiana R., Giunta M. (2011). Sustainable rehabilitation of porous European mixes - International Conference on Sustainable Design and Construction - ASCE Proceedings, Kansas City, March 23-25, 2011, Kansas City.

[10] Praticò F.G., Vaiana R., Giunta M. (2011). Recycling PEMs back to innovative, silent, permeable road surfaces - ICEE - International Conference on Environmental Engineering - Vilnius, LITHUANIA, ISSN 2029-7092, n. 5, pp. 1186-1192.

[11] Raaberg, J., Bendtsen, H. (2003). "Permeability of double-layer porous asphalt pavement." in Proc., 25th Baltic International Road Conference and Exhibition 25-27 August 2003, Vilnius, Lithuania.

[12] Chehovits, J. and Galehouse, L. (2010) - "Energy Usage and Greenhouse Gas Emissions of Pavement Preservation Processes for Asphalt Concrete Pavements". Proc. Transportation Research Board 89th Annual Conference, Washington DC.

[13] Kallas, B. F. (1984). "Flexible Pavement Mixture Design Using Reclaimed Asphalt Concrete," FHWA/RD-84/088, Final Report.27.

[14] Sullivan, J. (1996). "Pavement Recycling Executive Summary and Report," FHWA-SA-95-060, Final Report.

[15] Li, X., Marasteanu, M. O., Christopher W., and Clyne, T. R. (2008). "Effect of RAP (Proportion and Type) and Binder Grade on the Properties of Asphalt Mixtures," In Transportation Research Board 86th Annual Meeting Compendium of Papers CD-ROM, TRB, National Research Council.

[16] Rohde L., Ceratti J., Pereira A., Núñez Washington Peres, Vitorello T., (2008). Using Apt And Laboratory Testing To Evaluate The Performance Of High Modulus Asphalt Concrete For Base Courses In Brazil. Available 
on the Internet: <www.cedex.es/apt2008/html/.../Using_APT_and laboratory_testing.pdf $>$

[17] Barnes J., 2008, Bitumen Emulsion for Binding Dust from Stone Aggregate Surface, ISAET 26th September 2008.

[18] Praticò F.G., Moro A., Ammendola R., 2009. Factors affecting variance and bias of non-nuclear density gauges for PEM and DGFC, The Baltic Journal of Road and Bridge Engineering, 4(3): 99-107.

[19] Pratico' F.G., Moro A., Ammendola R., 2009. Modeling HMA Bulk Specific Gravities: a Theoretical and Experimental Investigation, International Journal of Pavement Research and Technology, 2(3):115-122.

[20] Wambold J.C., Henry J.J., Hegmon R.R., 1982. Evaluation of pavement surface texture significance and measurement techniques, Wear, Volume 83, Issue 2, 15, Pages 351-368.

[21] Boscaino G., Praticò F.G., (2001). A classification of surface texture indices of pavement surfaces [Classification et inventaire des indicateurs de la texture superficielle des revêtements des chaussées], Bulletin des Laboratoires des Ponts et Chaussees, Issue 234, Pages 17$34+123+125+127$.

[22] Cooley, L.A.; Prowell, B.D. and Brown, E.R. (2002). Issues Pertaining to the Permeability Characteristics of Coarse-Graded Superpave Mixes. NCAT Report No. 02-06. National Center for Asphalt Technology. Auburn, AL.

[23] Praticò F.G., (2004)." A theoretical and experimental Study of the effects on mixes added with RAP caused by Superpave restricted zone violation." Journal of Road Materials and Pavement Design, vol. 5, no1, pp. 73-91.

[24] Solaimanian M., Savory E. (2007), Variability Analysis of Hot-Mix Asphalt Concrete Containing High Percentage of Reclaimed Asphalt Pavement, Transportation Research Record, Transportation Research Board of the National Academies, ISSN 0361-1981, Volume 1543/1996.

[25] Mucinis D., Sivilevicius H., Oginskas R., 2009. Factors Determining the Inhomogeneity of Reclaimed Asphalt Pavement and Estimation of its Components Content Variation Parameters, Baltic Journal of Road and Bridge Engineering, Volume: 4, Issue Number: 2, Vilnius Gediminas Technical University, pp 69-79.

[26] Valdés G., Pérez-Jiménez F., Miró R., Martínez A., Botella R., 2011. Experimental study of recycled asphalt mixtures with high percentages of reclaimed asphalt pavement (RAP), Construction and Building Materials, Volume 25, Issue 3, Pages 1289-1297.

[27] Praticò F. G, Vaiana R., Giunta M. S., - Environmental sustainability of road pavements: Permeable wearing courses from recycling of Porous European Mixes (PEM) - Journal of Architectural Engineering, ASCE, ISSN: 1076-0431; UNDER REVIEW

[28] Praticò F. G, Vaiana R., Giunta M. S., - RAP variability in PEM recycling: environmental and technical issues - Journal of Civil Engineering and Architecture, ISSN:1934-7359; UNDER REVIEW. 
[29] Chen, M., Lin, J., Wu, S., Potential of recycled fine aggregates powder as filler in asphalt mixture 2011 Construction and Building Materials 25 (10), pp. 3909-3914.

[30] Suresha, S.N., Varghese, G., Ravi Shankar, Properties of cellulose fibres and waste plastic modified porous friction course mixes A.U. 2010 Baltic Journal of Road and Bridge Engineering 5 (3), pp. 156-163.

[31] Alvarez, A.E, Fernandez, E.M, Epps Martin, A., Reyes, O.J., Simate, G.S., Walubita, L.F., Comparison of permeable friction course mixtures fabricated using asphalt rubber and performance-grade asphalt binders, Construction and building materials, DOI: 10.1016/ j.conbuildmat.2011.08.085, Volume 28, Issue 1, March 2012, Pages 427436.

[32] Gedafa, D.S., Hossain, M., Ingram, L.S. and Kreider, R. (2011). "Performance-Related Specifications for PCC Pavements in Kansas." Journal of Materials in Civil Engineering doi:10.1061/(ASCE)MT.19435533.0000405 .

[33] Eamon C., Jensen E., Grace N., Shi X., Life Cycle Cost Analysis of Alternative Reinforcement Materials for Bridge Superstructures Considering Cost and Maintenance Uncertainties, Journal of Materials in Civil Engineering, forthcoming.

[34] Praticò F.G., Sireesh S., Puppala A., Comprehensive Life Cycle Cost Analysis for the Selection of Stabilization Alternatives for Better Performance of Low Volume Roads, Journal of the Transportation Research Board, No 2203, volume 2, pp 120-129, ISSN 0361-1981 ISBN 978-0-309-16085-8.

[35] Praticò F.G., Casciano A., Tramontana D., Pavement Life Cycle Cost and Asphalt Binder quality: A theoretical and experimental investigation, Journal of Construction Engineering and Management, 2011. ISSN: 07339364, 2011. 